\title{
Incidence and isolation of Bacteroides species from clinical material and their sensitivity to antibiotics
}

\author{
A. A. B. MITCHELL \\ From Law Hospital, Carluke, Lanarkshire
}

SYNOPSIS One thousand and sixty-seven strains of anaerobic Gram-negative bacilli were isolated from routine clinical material between January 1971 and December 1972. Most of the strains were isolated from sites allied to the lower intestine and genito-urinary tract. Resistance to tetracycline was present in $39.2 \%$ of strains tested. In contrast only one strain was found resistant to clindamycin. It is suggested that the recovery of anaerobes from material sent to the laboratory depends largely on the efficiency of the anaerobic system used.

Bacteroides are a group of Gram-negative, nonsporing anaerobic bacilli (Cowan and Steel, 1965). Gillespie and Guy (1956), in a review of the earlier literature, showed that they are the predominating organism in the lower intestine and had been isolated from appendicitis, postpartum infections, septicaemia, lung abscesses, and abdominal infections. Tillotson and Lerner (1968), reviewing mainly the American literature, pointed out the increased awareness that tonsillar cysts, carious teeth, the intestines, and vagina meet the fastidious anaerobic requirements of bacteroides and that this is corroborated by the isolation of bacteroides from sinusitis, otitis media, meningitis, bacteraemia, endometritis, pelvic thrombophlebitis, intraabdominal abscesses, and empyema. Rotherman and Schick (1970) stated that $\boldsymbol{B}$. fragilis was the most common anaerobic Gram-negative bacillus isolated in cases of septic abortion and suggest that this finding establishes the role of these organisms as major pathogens. In a study of the antibiotic sensitivity of $B$. fragilis, Ingham, Selkon, Codd, and Hale (1968) isolated five out of 55 representative strains from abscesses. Felner and Dowell (1970) reported the isolation of $B$. fragilis from nine patients suffering from anaerobic bacterial endocarditis, and Mitchell and Simpson (1973) reported bacteroides septicaemia in five patients following abdominal surgery.

This study was carried out between January 1971 and December 1972, the object being to determine the frequency of isolation of bacteroides from routine clinical specimens received in this laboratory. Received for publication 24 July 1973.

\section{Material and Methods}

Specimens from the upper respiratory tract were omitted, as were specimens of urine (except for a small selected series). No special precautions were taken to preserve anaerobic organisms during transit of specimens of pus to the laboratorys Vaginal swabs were normally delivered to the laboratory in Stuart's transport medium (Oxoid) and this was found to preserve bacteroides satisfactorily. From mid 1972 this medium has been used to preserve specimens of pus collected during the night when the laboratory is closed.

No attempt was made to isolate bacteroides on primary culture routinely. All specimens were incubated overnight in Robertson's cooked meat broth. These were subcultured onto either (a) blood agar containing $100 \mu \mathrm{g} / \mathrm{ml}$ neomycin, which will also permit the growth of $\mathrm{Cl}$. welchii, Str. faecalis, anaerobic streptococci, and actinomyces sp, and/ or (b) blood agar containing $100 \mu \mathrm{g} / \mathrm{ml}$ neomycin and $10 \mu \mathrm{g} / \mathrm{ml}$ vancomycin which normally inhibits all Gram-positive bacteria. The plates were then incubated anaerobically overnight, using the GasPak system (BBL) which contains a mixture of hydrogen $+5 \%$ carbon dioxide.

\section{BLOOD CULTURES}

In this laboratory the routine medium used is 0 tryptose phosphate broth $(50 \mathrm{ml})$, to which $5-10 \mathrm{ml}$ blood is added into a rubber sealed bottle. Bacteroides can be isolated from this medium after four to five days' incubation. 


\section{BIOCHEMICAL TESTS}

One per cent peptone water sugars containing glucose, lactose, sucrose, mannitol, and maltose in bijoux bottles with loose fitting caps were incubated anaerobically for 48 to 72 hours.

\section{ADDITIONAL TESTS}

Growth on bile salt medium using MacConkey agar no. 2 (Oxoid) and the effect of haematin on growth using blood agar base no. 2 (Oxoid) and $\mathrm{X}$ factor discs (Oxoid) were also estimated.

\section{ANTIBIOTIC SENSITIVITY TESTS}

These were carried out by the disc diffusion method (Multidisk, Oxoid) on blood agar plates which were incubated overnight anaerobically. The following antibiotics were tested: penicillin $1.5 \mu \mathrm{g}$, streptomycin $10 \mu \mathrm{g}$, tetracycline $10 \mu \mathrm{g}$, methicillin $10 \mu \mathrm{g}$, gentamicin $10 \mu \mathrm{g}$, neomycin $10 \mu \mathrm{g}$, fusidic acid $10 \mu \mathrm{g}$, clindamycin $2 \mu \mathrm{g}$, erythromycin $2 \mu \mathrm{g}$, rifampicin $30 \mu \mathrm{g}$, chloramphenicol $50 \mu \mathrm{g}$, carbenicillin $100 \mu \mathrm{g}$, cephalothin $30 \mu \mathrm{g}$, cephalexin $30 \mu \mathrm{g}$, cephaloridine $30 \mu \mathrm{g}$, and colostin $10 \mu \mathrm{g}$.

\section{OTHER ANTIBACTERIAL AGENTS}

Filter paper discs impregnated with $1 \%$ solutions of Dettol and Savlon were prepared and stored at $4^{\circ} \mathrm{C}$, as were discs containing $10 \mu \mathrm{g}$ metrodiazole (Flagyl).

\section{Results}

In this study, the isolation of Gram-negative, anaerobic bacilli was sufficient for them to be named as Bacteroides species. Further detailed attempts at identification were initially based on biochemical activity and subsequently on the susceptibility to various antibiotics.

\section{BIOCHEMICAL TESTS}

The first 42 strains isolated were examined in some detail. All grew in $1 \%$ peptone water sugars anaerobically and acid was produced from glucose, lactose, maltose, and sucrose. Mannitol was not attacked nor was indole produced. No haemolysis or pigment was observed in blood agar. All strains grew on MacConkey agar. Growth was poor on blood agar base no. 2 (Oxoid), but was markedly improved by the addition of haematin ( $X$ factor discs, Oxoid). Morphologically these isolates were small Gram-negative coccobacilli. Such strains were resistant to penicllin, neomycin, cloxacillin, and gentamicin and sensitive to clindamicin and erythromycin. These strains and subsequent isolates with the same antibiotic resistance pattern were considered to be Bacteroides fragilis. Strains which deviated from this antibiotic resistance pattern were examined in more detail. Nine such strains were isolated and produced larger colonies on blood agar than did $B$. fragilis and microscopically appeared as large Gram-negative pleomorphic bacilli with numerous filaments. In addition to being sensitive to penicillin, these isolates were all uniformly resistant to fusidic acid and rifampicin (to which $B$. fragilis is normally sensitive) and sensitive to colistin to which $B$. fragilis is resistant. These strains were identified as Sphaerophorus species.

\section{SOURCE OF STRAINS}

Table I shows the source of strains isolated during the two-year period. The sites from which anaerobic Gram-negative bacilli were isolated from pus are shown in table II.

\begin{tabular}{llc}
\hline Source & $\begin{array}{l}\text { No. of Specimens } \\
\text { Examined }\end{array}$ & $\begin{array}{l}\text { No. of Specimens Con- } \\
\text { taining Gram-negative } \\
\text { Anaerobic Bacilli }\end{array}$ \\
\hline Pus (all sources) & 6977 & 256 \\
Vaginal swabs & 4414 & 762 \\
Ear swabs & 422 & 26 \\
Urines & 114 & 17 \\
Cerebrospinal fluid & 252 & 1 \\
Blood cultures & 612 & 5 \\
& & 1067 \\
\hline
\end{tabular}

Table I Sources from which Bacteroides were isolated

\begin{tabular}{lc}
\hline Site & No. of Isolations \\
\hline Lower abdominal wounds & 109 \\
Appendicectomies & 80 \\
Ischio-rectal abscesses & 11 \\
Bed sores & 24 \\
Varicose ulcers & 1 \\
Amputation wounds & 6 \\
Pilonidal sinus & 6 \\
Chest-wall sinus & 2 \\
Leg sinus & 2 \\
Recto-vaginal sinus & 1 \\
Abdominal abscess & 3 \\
Pelvic abscess & 1 \\
Perianal abscess & 4 \\
Thigh sinus & 1 \\
Groin abscess & 1 \\
Cheek abscess & 1 \\
Pleural cavity & 1 \\
Scrotal abscess & 1 \\
Buttock abscess & 1 \\
& 256 \\
\hline
\end{tabular}

Table II Sources of pus from which Bacteroides were isolated

Seven hundred and fifty-nine isolations of bacteroides and three isolations of sphaerophorus were made from 4414 vaginal swabs. Routine antenatal swabs produced 251 positive cultures and 307 were isolated from postnatal patients who were pyrexial and/or had a foul-smelling lochia. The majority of these cultures were obtained from women who had 
either an induced rupture of the membranes or a Caesarian section. The remaining 204 isolates came from women suffering from 'vaginitis'.

Bacteroides were isolated on 26 occasions from 422 patients with infected ears. Eighteen gave a history of chronic suppurative otitis media. In many instances the production of 'foul-smelling pus' was noted. One patient who had suffered a head injury subsequently developed meningitis, and Proteus and $B$. fragilis were isolated from cerebrospinal fluid.

One hundred and fourteen midstream urine specimens, 77 from females, were examined for the presence of bacteroides. Seventeen strains were isolated from 16 female patients; no bacteroides were isolated from males. In seven instances there were a significant number of aerobic organisms (more than $100000 / \mathrm{ml}$ ), but in the remaining 10 isolations were made in the absence of a significant number of aerobic bacteria, and in six cases the centrifuged urine had less than five leucocytes present per high-power field. In this series of urines, 21 specimens were from antenatal patients. Vaginal swabs from the patients were examined for bacteroides on the same day as the urine specimens. Three vaginal swabs produced positive cultures and two urines were also positive. In only one instance was the urine and the vaginal swab from the same patient positive. Both urines had neither leucocytes nor a significant number of aerobic bacteria.

Anaerobic Gram-negative bacilli were isolated from five out of 612 blood cultures examined. In each instance septicaemia followed abdominal surgery in patients over 65 years of age. In each case

\begin{tabular}{lcc}
\hline Antibiotic & No. Strains Tested & No. Strains Sensitive \\
\hline Penicillin & 1067 & $9^{1}$ \\
Streptomycin & 1067 & Nil \\
Gentamicin & 1067 & Nil \\
Neomycin & 1067 & Nil \\
Methicillin & 1067 & Nil \\
Tetracycline & 1067 & 651 \\
Fusidic acid & 794 & $779^{1}$ \\
Clindamycin & 1067 & 1066 \\
Erythromycin & 275 & 272 \\
Rifampicin & 63 & $54^{1}$ \\
Chloramphenicol & 25 & 25 \\
Carbenicillin & 44 & 41 \\
Cephaloridine & 6 & Nil \\
Cephalothin & 6 & Nil \\
Cephalexin & 6 & Nil \\
Colistin & 46 & 91 \\
\% Dettol & 25 & 25 \\
1\% Savlon & 25 & 25 \\
10 M Flagyl & 25 & 25 \\
\hline
\end{tabular}

Table III The susceptibility of Bacteroides to various antimicrobial agents

1The nine strains sensitive to penicillin were also sensitive to colostin but resistant to fusidic acid and rifampicin and were regarded as being Sphaerophorus sp. growth of anaerobic bacteria was only detected after four to five days' incubation.

\section{ANTIBIOTIC SENSITIVITY}

Table III shows the results of testing a number of strains of anaerobic Gram-negative bacilli against various antimicrobial drugs.

Dettol and Savlon were tested as an example of antiseptics which are commonly used in obstetrics and gynaecology. Flagyl is generally used in the treatment of trichomonal infections but has also been shown to be bactericidal to bacteroides (Nastro and Finegold, 1972).

\section{Discussion}

As a result of being part of the normal bacteriological flora of the lower intestine, it may often be difficult to assess if and when bacteroides are acting as commensals or potential pathogens. If they are isolated in pure culture and the patient responds clinically to specific chemotherapy, their pathogenic role in these instances is proven. However, the technical difficulties involved in isolating bacteroides may be considerable and time consuming. As a result, their presence may b\& missed and only the more easily isolated aerobie bacteria will be reported. In the five instance where bacteroides were isolated from blood cultures ${ }^{+}$ their presence was not detected until the culture bottles had been incubated for four or five days (Mitchell and Simpson, 1973). Therefore, the recommendation by Gunn (1957) that if bacteroides infection is suspected treatment should be commenced before the bacteriological report is available seems to be justifiable.

A feature of anaerobic culture work which is not always appreciated is that it takes several hours for an anaerobic jar, especially a metal one, to heat up to $37^{\circ} \mathrm{C}$. This means that if a jar which has been kept at room temperature all day is incubated late in the afternoon, and then re-opened first thing the next morning, the contents of the jar may have been at $37^{\circ} \mathrm{C}$ for less than 12 hours. This might be satisfactory for rapidly growing organisms like Cl. welchii but it is probably not long enough for o bacteroides. The habit of storing empty anaerobic $\tilde{N}$ jars in the incubator when not in use is recommended, as the temperature lag is reduced.

Gillespie and Guy (1957) reported that all the strains they tested were sensitive to tetracycline. Bodner, $\stackrel{\complement}{\mathbb{\Phi}}$ Koenig, Treanor, and Goodman (1972) found that $\stackrel{?}{?}$ only $40 \%$ of strains of $B$. fragilis were sensitive to tetracycline. In this series, $60.8 \%$ were found to be sensitive. This increase in tetracycline resistance since 1957 is unfortunate as it reduces the number 
of broad-spectrum antibiotics which can be used to treat both coliform and bacteroides infections where there is doubt as to which organism is responsible for the septic condition. Chloramphenicol would seldom be used because of its dangerous side effects, and at present there is no information as to the effectiveness in vivo of carbenicillin against bacteroides.

Ingham, Selkon, Codd, and Hale (1970) showed that $0.3 \mu \mathrm{g}-1.25 \mu \mathrm{g}$ clindamycin was bactericidal to strains of $\boldsymbol{B}$. fragilis. The high sensitivity of bacteroides to clindamycin and to a slightly lesser extent, the parent compound, lincomycin, has been confirmed by Kislak (1972), Bodner et al (1972), and Martin, Gardner, and Washington (1972). In this series only one of 1067 strains tested was found to be resistant to clindamycin. Geddes, Munro, Murdoch, Begg, and Burns (1967) and Tracy, Gordon, Moran, Love, and McKenzie (1972) have reported the successful use of lincomycin in treating bacteroides infections, and Mitchell and Simpson (1973) have reported on the use of clindamycin in treating bacteroides septicaemia.

\section{References}

Bodner, S. J., Koenig, M. G., Treanor, L. L., and Goodman, J. S.
(1972). Antibiotic susceptibility testing of bacteroides. Antimicrob. Agents and Chemother., 2, 57-60.

Cowan, S. T., and Steel, K. J. (1965). Manual for the Identification of Medical Bacteria. Cambridge University Press, Cambridge.

Felner, J. M., and Dowell, V. R. Jr., (1970). Anaerobic bacterial endocarditis. New Engl. J. Med., 283, 1188-1192.

Goddes, A. M., Munro, J. F., Murdoch, J. McC., Begg, K. J., and Burns, B. A. (1967). In Proceedings of the Sth International Congress of Chemotherapy, 1, p. 367, edited by K.H. Spitzy and H. Haschek, Vol. 1, p. 367. Wiener Medizinische Akademie, Vienna.

Gillespie, W. A., and Guy, J. (1956). Bacteroides in intra-abdominal sepsis. Lancet, 1, 1039-1041.

Gunn, A. A., (1957). Bacteroides infection in the surgery of childhood. Arch. Dis. Childh., 32, 523-529.

Ingham, H. R., Selkon, J. B., Codd, A. A., and Hale, J. H. (1968). A study in vitro of the sensitivity to antibiotics of Bacteroides fragilis. J. clin. Path., 21, 432-436.

Kislak, J. W. (1972). The susceptibility of Bacteroides fragilis to 24 antibiotics. J. infect. Dis., 125, 295-299.

Marrin, W. J., Gardner, M., and Washington, J. A., II. (1972). In vitro entimicrobial susceptibility of anaerobic bacteria isolated from clinical specimens. Antimicrob. Agents and Chemother., n.s., $1,148-158$.

Mitchell, A. A. B., and Simpson, R. G. (1973). Bacteroides septicaemia. Ann. med. Res. Opin., 1, 385-389.

Nastro, L. J., and Finegold, S. M. (1972). Bactericidal activity of five antimicrobial agents against Bacteroides fragilis. J. infect. Dis., 126, 104-107.

Rotheram, E. B., Jr., and Schick, F. (1969). Nonclostridial anaerobic bacteria in septic abortion. Amer. J. Med., 46, 80-89.

Tillotson, J. R., and Lerner, A. M. (1968). Bacteroides pneumonias: characteristics of cases with empyema. Ann. intern. Med., 68, 308-317.

Tracy, O., Gordon, A. M., Moran, F., Love, W. C., McKenzie, P. (1972) Lincomycins in the treatment of Bacteroides infections. Brit. med. J., 1, 280-282. 